\section{Participatory GIS in Mapping Ecosystem Services: Two Case Studies from High-Biodiversity Regions in Italy and Peru}

GI_Forum 2017, Issue 2 Page: 78 - 96

Full Paper

Corresponding Author: daniele.codato@unipd.it DOI: 10.1553/giscience2017_02_s78

\author{
Daniele Codato, Salvatore E. Pappalardo and Massimo de Marchi \\ Department of Civil, Environmental and Architectural Engineering, University of Padova
}

\begin{abstract}
Assessing ecosystem services (ES) and mapping their values are of paramount importance. Here we present two case studies where the participatory mapping of social values of landscape ecosystem services is used in territories with high levels of cultural and biological diversity (Adamello Brenta Natural Park in Italy and the Alto Mayo basin in the Western Amazon, Peru). A mixed-method approach combining social geography fieldwork (participatory mapping) and desk work (GIS analyses) is adopted to improve ES mapping by including multiple actors and to increase awareness. Mapping ecosystem services is not just a technical task; it also highlights social implications of the cartographic process, a key issue in human geography. By taking into account the controversial and multiple roles of maps, and by involving actors in attributing values and mapping their spatial relations to landscape and ES, it is possible to enrich technical knowledge with local knowledge.
\end{abstract}

\title{
Keywords:
}

social values, landscape ecosystem services, SoIVES, participatory GIS

\section{Introduction}

Since the 90s, the concept of ecosystem services (ES) - that is, the benefits people derive from ecosystems - has attracted growing interest from both academic and international organizations. Various definitions and classifications have been developed, such as the Millennium Ecosystem Assessment classification and the Common International Classification of ES [CICES]). Assessments and research projects have also been carried out, in an attempt to define an organic and easily adaptable framework suitable in different contexts (Hermann et al., 2011; MA, 2005).

The inclusion of the ES concept in processes of ecosystem evaluation and land management provides decision makers with a means of evaluating more holistically the social, economic and biophysical values of an area (Nahuelhual et al, 2016; Sherrouse et al., 2014; Bryan et al., 2010; MA, 2005). Ecosystems and their services have an intrinsic spatial connotation, and one of the main technical and conceptual challenges is their mapping, where the map goes 
beyond its strong communicational and educational characteristics and is a fundamental tool to understand and analyse this complex system (Hauck et al., 2013).

Mapping ES is not just a technical task belonging within the scientific and policy domains; it also opens up important questions regarding the social implications of the mapping process, which are a key issue in human geography.

Participation and inclusion of people in the production, interpretation, use, sharing and communication of spatial information and knowledge using geographic information system (GIS) technologies are key for a variety of scientific disciplines. Techniques and perspectives have evolved in different but not clearly distinct ways in developing and developed countries, which for simplicity can be (temporarily) distinguished as representing two main approaches: Participatory GIS (PGIS), more common in developing countries, and Public Participatory GIS (PPGIS), in developed countries (Brown \& Kytta, 2014; Rambaldi et al., 2006).

The goal of mapping ES through PGIS or PPGIS would include not only the production of maps but also the empowerment and inclusion of people by recognizing their spatial knowledge and opinions. Other key elements to include in the process are the spatial ES attributes to be mapped, the different ways to analyse data to produce maps, and the scale of the analysis (Brown, 2004).

Brown (2012) argued that the participatory mapping of ES using traditional ES classifications as attributes is very complex due to the high level of knowledge required. $\mathrm{He}$ proposed using the sense of place, or place perception framework, referred to in various fieldwork studies using different terms, such as 'place-based values', 'landscape values' and 'social values of ES' (Sherrouse et al., 2011). Social values of ES are defined as the 'perceived qualities carried by a natural environment that provide benefits to support human well-being' (Van Riper et al., 2012) or 'non-market values perceived by ecosystem stakeholders' (Sherrouse et al., 2014). In the context of our study, hereafter we use the term 'social values of landscape ES' to refer to all the previous concepts at a landscape scale.

A spatially explicit survey, combining the qualitative-quantitative methodology of questionnaires with spatial modelling, was elaborated and integrated into the GIS environment in order to map the social values of landscape ES. To define a methodology suitable for different contexts, we tested a spatially explicit survey in two different study areas that show high levels of cultural and biological diversity under various anthropogenic pressures, relevant land use planning for sustainable development in a high-mountain context, and varying levels of accessibility to ICT. The two case studies, within the 'Territories of ecological and cultural diversity' research project (University of Padua, Italy), are located in the Alto Mayo Andean-Amazon watershed (Peru) and the Adamello Brenta Natural Park (hereafter, PNAB), Trentino Province, Italy. In both cases, participatory processes for territory planning had already been activated. In the Alto Mayo area, an integrated watershed management project (the Biocuencas project) is being led by Conservation International Peru (an NGO) and the Regional Government of San Martín; in the PNAB, the landscape management plan was developed in line with the European Charter for Sustainable Tourism in Protected Areas. 
The general aim of this paper is to present a draft methodology to assess and map social values of landscape ES through participatory mapping methods in order to promote the incorporation of these social values in decision-making and territory planning. Specific aims are (i) to test the integrated spatially-explicit survey; (ii) to geovisualize hotspots for the social values of landscape ES; (iii) to highlight and compare the results of the perceptions of different actors in two different contexts, and (iv) to discuss and compare transferability of methods for fieldwork and desk work.

\section{Material and Methods}

Our research is based on a combination of methods and tools belonging to both quantitative and qualitative GIS (Kwan and Ding, 2008; Nyegers et al., 2011; De Marchi, 2013; Pappalardo et al., 2013). Survey methodologies for mapping the social values of landscape ES were adapted and implemented for the two study areas after being validated in the field by various key actors.

\section{The Adamello Brenta Natural Park, Italy}

The PNAB, with an area of $618.6 \mathrm{~km}^{2}$ and located in the Central Alps, Northern Italy, is a mosaic of cultural landscapes resulting from a long history of interactions between the local communities and the ecosystems (Figure 1). The park's administrative boundaries overlap the territories of 38 municipalities that have a total population of 45,550. Its natural assets consist of lakes, alpine pastures, forests and waterfalls, which are accessible by ski runs and more than $150 \mathrm{~km}$ of trails; these features, in addition to the wildlife, attract more than 7 million visitors per year (De Marchi \& Scolozzi, 2012).

We performed two surveys, one with tourists (43 questions) and the other with residents (38 questions), in order to gather spatial knowledge and spatial perceptions about the social values of landscape ES, and other information useful for landscape planning. The surveys were administered by trained interviewers to a sample of 268 tourists in car parks, park visitor centres, town squares and alpine huts. For the residents, the questionnaire was sent to local institutions, such as the municipalities belonging to the park; residents (556) were asked to complete the questionnaires themselves. A total of 226 responses were received.

In addition to questions relating to personal information and people's knowledge of the park's territory, two specific questions were oriented towards mapping the social values of landscape ES:

- From the following list of 9 social values of landscape ES, choose a maximum of 3 and list in order of importance, from lowest to highest: (i) the open views, the colours of the seasons, the silence and the smell of the place (scenic/aesthetic);( ii) the history and traditions of the places (historic/cultural); (iii) the wilderness (naturalistic); (iv) the role of the local economy (economic); (v) the contribution to physical and mental well-being (therapeutic); (vi) opportunities for sports and leisure 
(recreational); (vii) air, water and soil quality (environmental/life-sustaining); (viii) biodiversity (biodiversity); and (ix) opportunities for increasing knowledge about nature and human action (knowledge \& learning).

- We asked respondents to provide a maximum of four places in order of importance (assigning to each a score of 50,30,15 or 5, from most to least important) for each landscape value: $4 \times 9=36$ places, max., in total. In order to reduce the time spent completing the survey, participants did not work directly with maps.

Information related to all places identified by participants was extracted from the two surveys and then processed into a GIS platform. A point shapefile was created that digitalized the locations in ArcMAP 10.1 TM (ESRI), using as reference the cartographic base of the Park; for every location, an attribute table was created for the different landscape ES values, and a related score for each attribute was calculated, which was the sum of the individual scores.

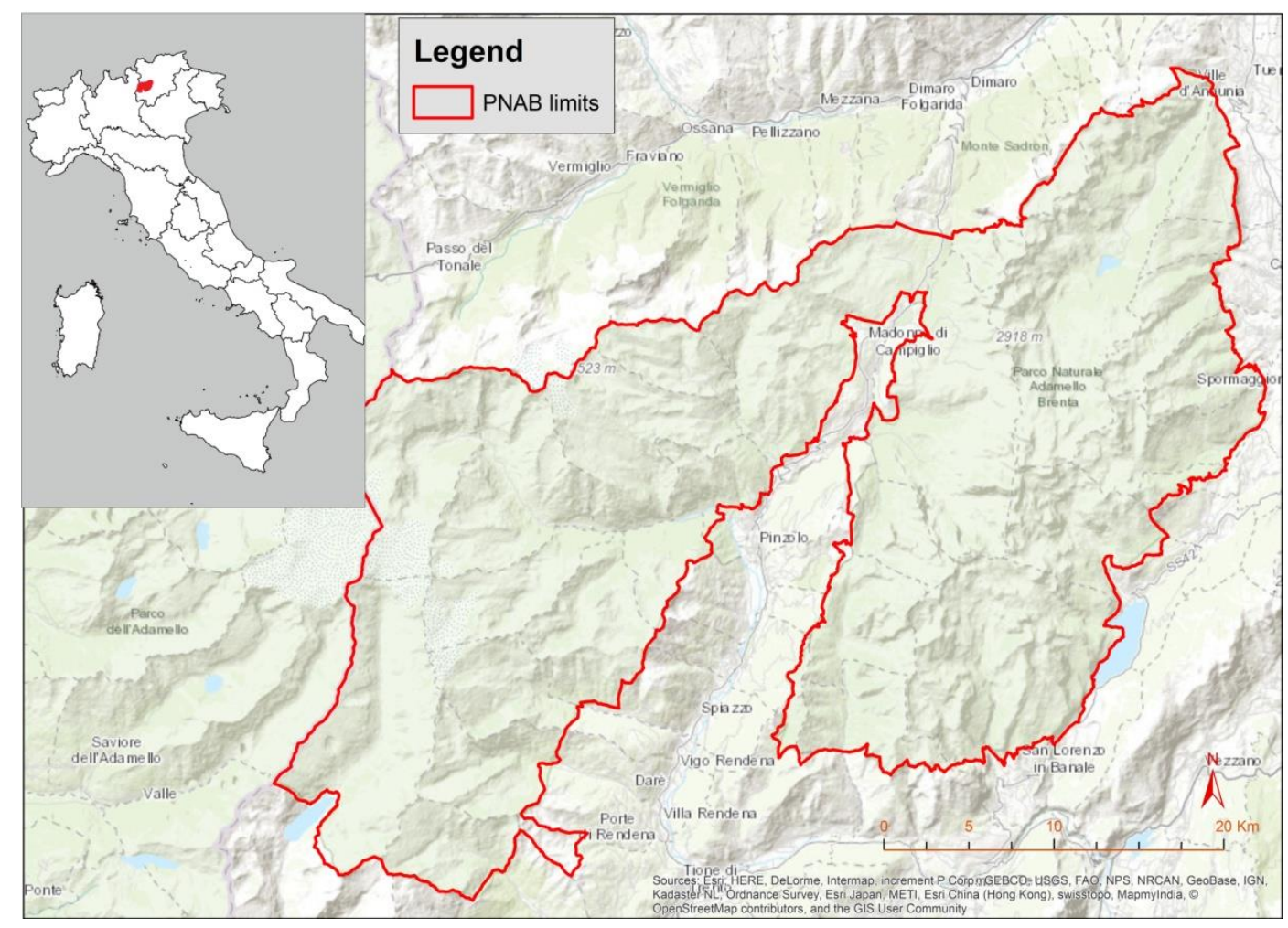

Figure 1: The PNAB territory (basemap ESRI) 


\section{The Alto Mayo case study}

Alto Mayo, with a population of about 263,000, comprises the provinces of Rioja and Moyobamba, covering an area of $6,620 \mathrm{~km}^{2}$ within the region of San Martín, Peru (Figure 2). It is part of the Andean-Amazon Basin, which offers a wide variety of ES and unusual characteristics, mainly thanks to its highly biodiverse tropical forest ecosystems and its cultural diversity, represented by the presence of indigenous communities. It is also a territory which, for the last 50 years, has experienced drastic transformations that have had negative impacts on both human and natural capital. These effects have been related mainly to anthropogenic pressures on ecosystems, which are driven by uncontrolled expansion of agriculture (coffee, rice, corn and cocoa), and the growing deforestation processes of the primary tropical forest. The rapid increase in land-use change could lead to a decline in quality of life, provoking a degradation of ES. In the last 10 years, the Regional Government of San Martín, with the collaboration of various NGOs and other agencies, has carried out several initiatives to reverse the environmental degradation processes with the aim of creating a 'San Martín Green Region toward 2021' (Codato, 2015).

In this context, we developed surveys in the field, including participatory mapping work. We also collected all available secondary data, mainly in GIS formats such as vector or raster data, biological and social studies, political information and land-use plans. The surveys and PGIS work were based on previous studies (De Marchi \& Scolozzi, 2012; Sherrouse et al., 2011). Our dataset is based on 375 surveys of inhabitants of Alto Mayo and 100 surveys of key actors. The two survey targets were distributed proportionally and stratified in the various urban and rural areas of Alto Mayo. In our analysis, the most important characteristics of the people surveyed were: (i) work position (we interviewed mainly teachers and farmers); (ii) origin and group identity (indigenous, new settlers arriving a maximum of 10 years before, and old settlers), and (iii) affiliation to organizations and institutions. The key actors were public administration organizations; key persons were representatives from local organizations (i.e. farmer organizations, indigenous communities, local NGOs).

We investigated the following issues:

- Ranking of seven social values of landscape ES by progressive values from 1 (least importance) to 7 (greatest importance): scenic/aesthetic value, biodiversity value, use/economic value, environmental/life-sustaining value, recreational value, spiritual/cultural value and historic value. It is worth noting that social values of landscape ES were reduced in number from 9 to 7 in order to simplify the work because of a high level of illiteracy, and we considered a new category, spiritual/cultural value, due to the presence of indigenous peoples.

- Every participant was asked to mark the five most important social values on a paper map of Alto Mayo (1:210,000 scale, in A2 format). For any one value, interviewees were allowed to identify up to four specific sites or areas as being particularly important.

- Other questions covered participants' knowledge, personal information, and general opinions about the socio-environmental impacts in the area. 
In order to digitize and georeference all sites marked on the paper maps during fieldwork activities, information and spatial data were processed in ArcGIS 9.3 ${ }^{\mathrm{TM}}$ (ESRI).

Thus, for every social value, a point kernel density analysis with a search radius of $210 \mathrm{~m}$ (based on the paper map scale) was performed in order to obtain maps pinpointing the most valued places. We also used the GIS-based tool Social Values for Ecosystem Service (SolVES), which is specifically designed to quantify the perceived social values of a series of ES through a quantitative, 10-point social-values metric, the Value Index (Sherrouse et al., 2011). SolVES version 2.1 integrates the Maxent maximum entropy modelling software, which produces maps and statistics that integrate the social values of ES distribution with the layers that the user introduced into the system - in this case, rasters about land use and land cover, the important sub-watersheds, the area occupied by different protected areas, and indigenous communities (Sherrouse, 2014).

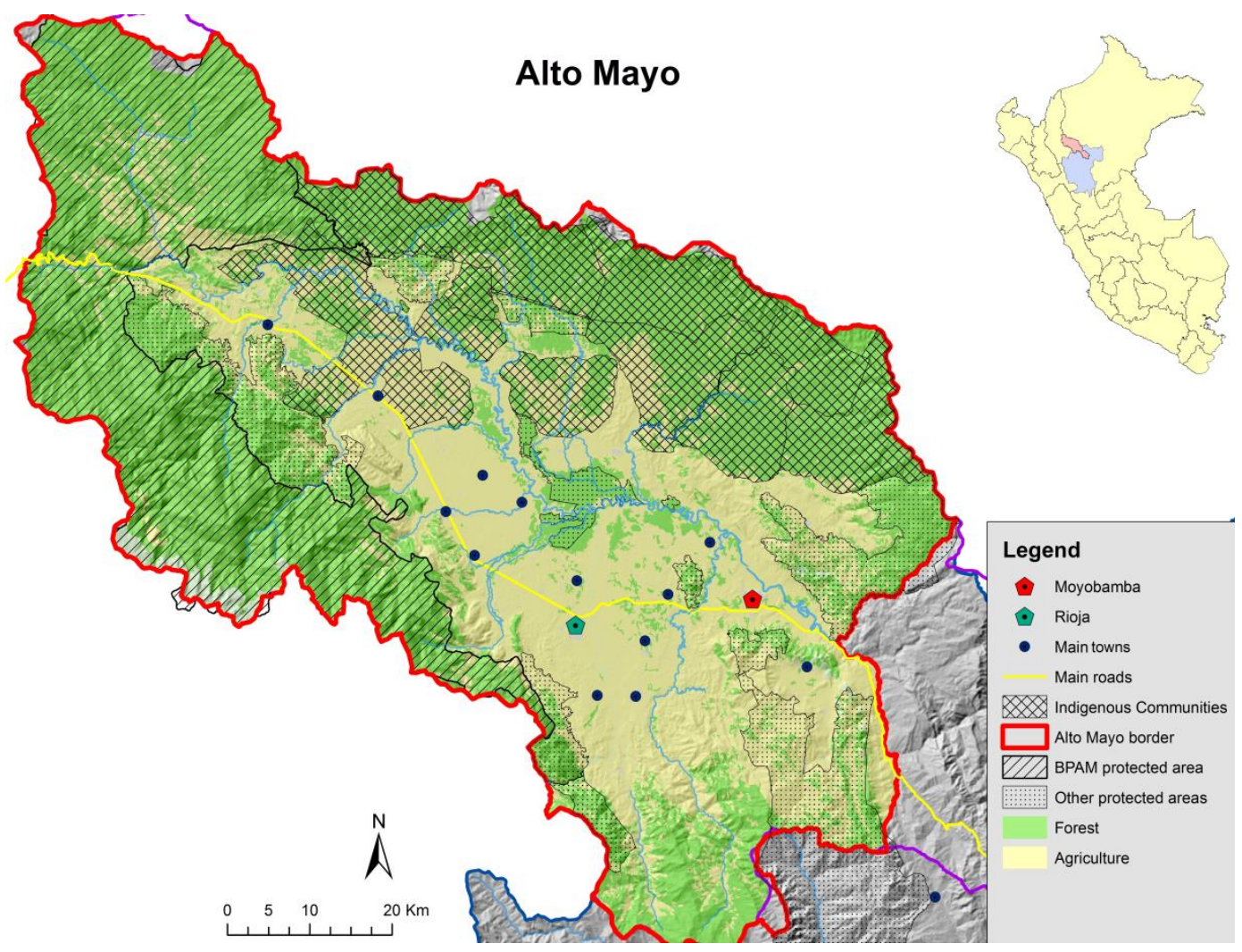

Figure 2: Alto Mayo territory. Highlighted are the main protected areas (i.e., the 'Bosque de Protección Alto Mayo' (BPAM)), other protected areas, the indigenous communities, the main towns and the two province capitals, Moyobamba and Rioja. 


\section{Results and Discussion}

\section{The PNAB}

In the PNAB, the questionnaire investigated preferences regarding nine social values of landscape ES. From the tourists' perspective, most important was the scenic/aesthetic value, while the second was the environmental value (Figure 3). By contrast, residents highlighted scenic/aesthetic and historic/cultural values as the two main ES values (Figure 3). Concerning the knowledge \& learning and economic values, residents and tourists expressed the same ranking (Figures 3). Maps in Figures 4-5 and 6-7 show results for the first two social values of landscape ES, from the tourists' and residents' perspectives respectively. For scenic/aesthetic value, for tourists and residents alike, the most valuable places were the most popular tourist sites, the highest mountain peaks and the lakes. For environmental values, tourists rated some places outside the park with a high value. For historic/cultural values, various places with great historical significance, such as an association with the First World War, were recognized by residents.

From one perspective, the fact that tourists chose various places outside the administrative limits of the park reveals a lack of knowledge of the park's administrative extent; from another perspective, it means that naturalness and environments outside boundaries were perceived as being important. The 10-15 places that were the most cited by tourists and residents were perceived as icons for the park. For tourists, in first place was Val Genova, followed by other key locations, such as the Lake of Tovel and the Val Algone, the Cornisello, the Valagola, the various waterfalls, and the Val di Fumo.

The key elements in the appreciation of these places were aesthetics, panoramas of particular beauty, and naturalness. For residents, social values of landscape ES related to places with an emotional dimension and tranquillity, which highlighted how much the landscape is invested with immaterial values. Elements of a landscape are important not simply for their physical or structural appearance (high mountain peaks, waterfalls etc.) but also for the astonishment and pleasure that these features induce. 


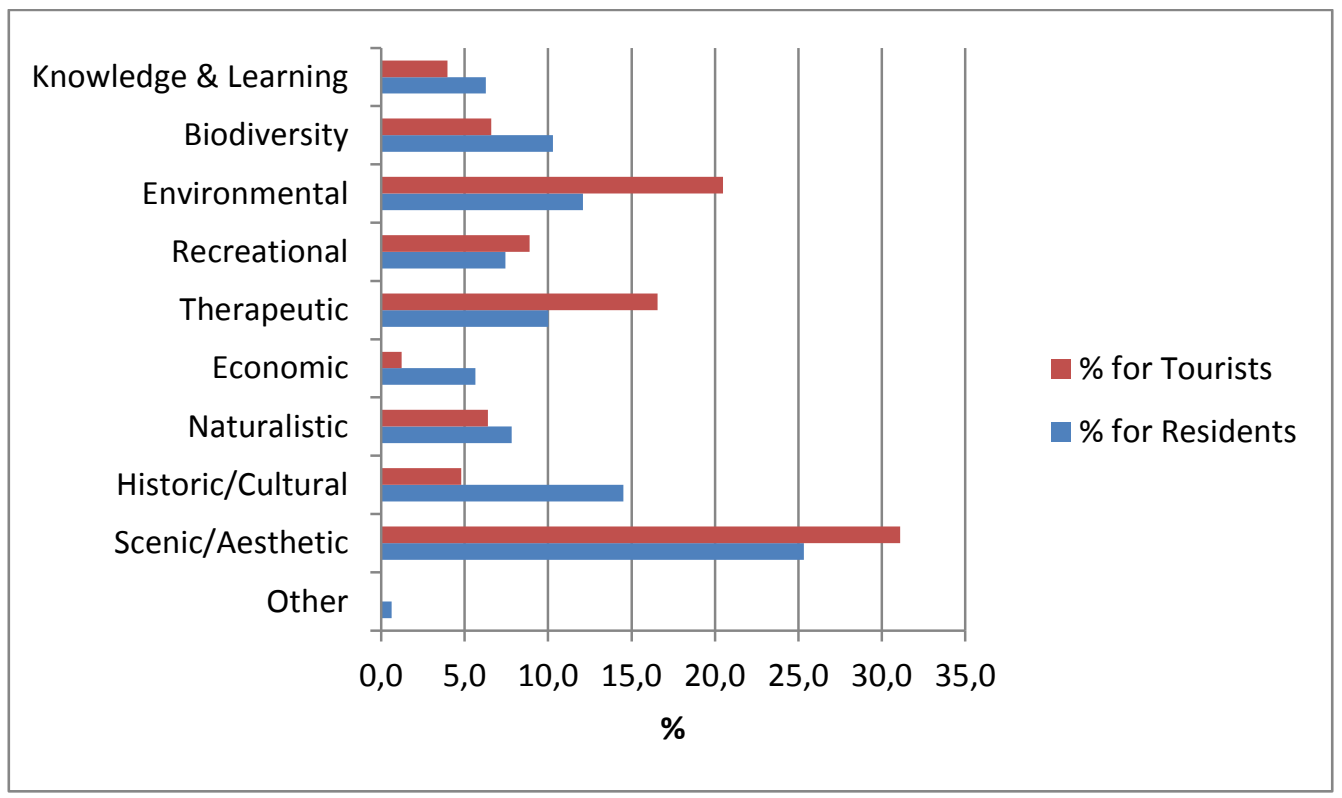

Figure 3: Tourists' and Residents' preferences concerning the social values of landscape ES of the PNAB

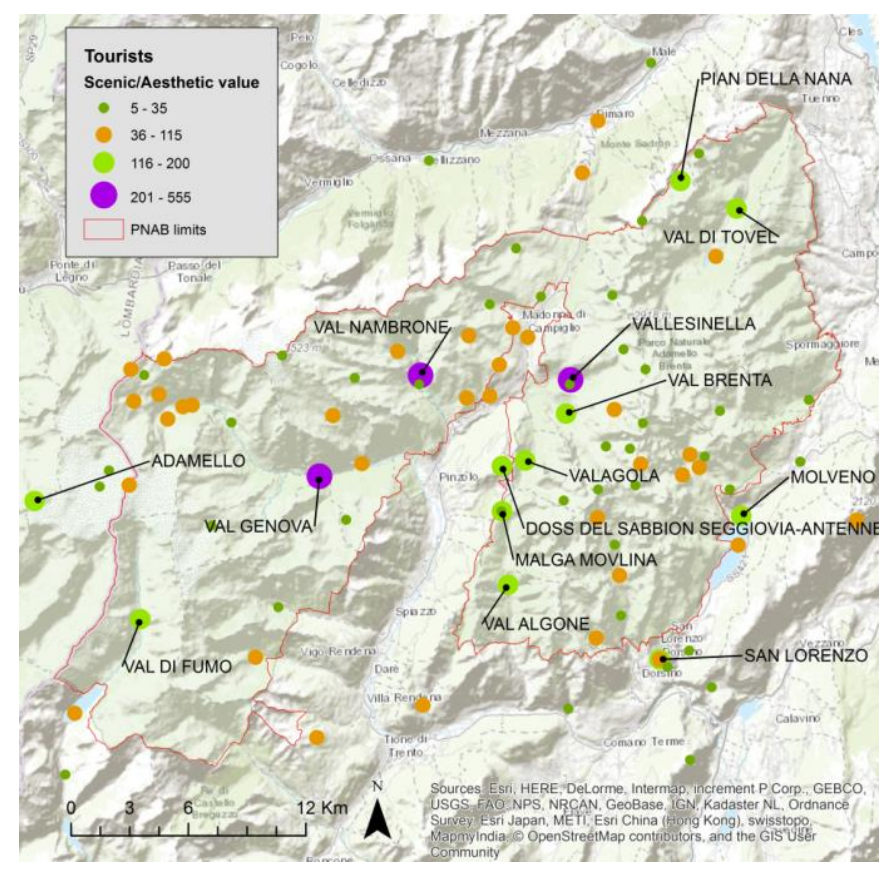

Figure 4: Scenic/aesthetic value for tourists. Dots of different colours represent the places mentioned by the participants: the larger the dot, the higher the feature scored. 


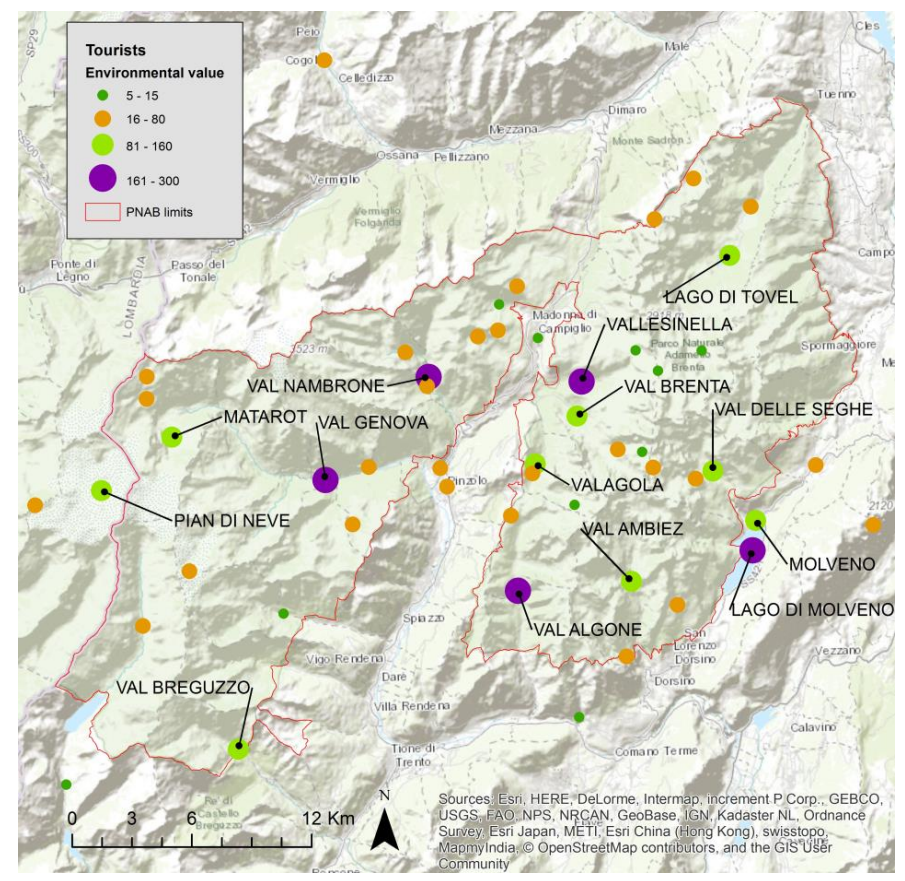

Figure 5. Environmental value for tourists. Dots of different colours represent the places mentioned by the participants: the larger the dot, the higher the feature scored.

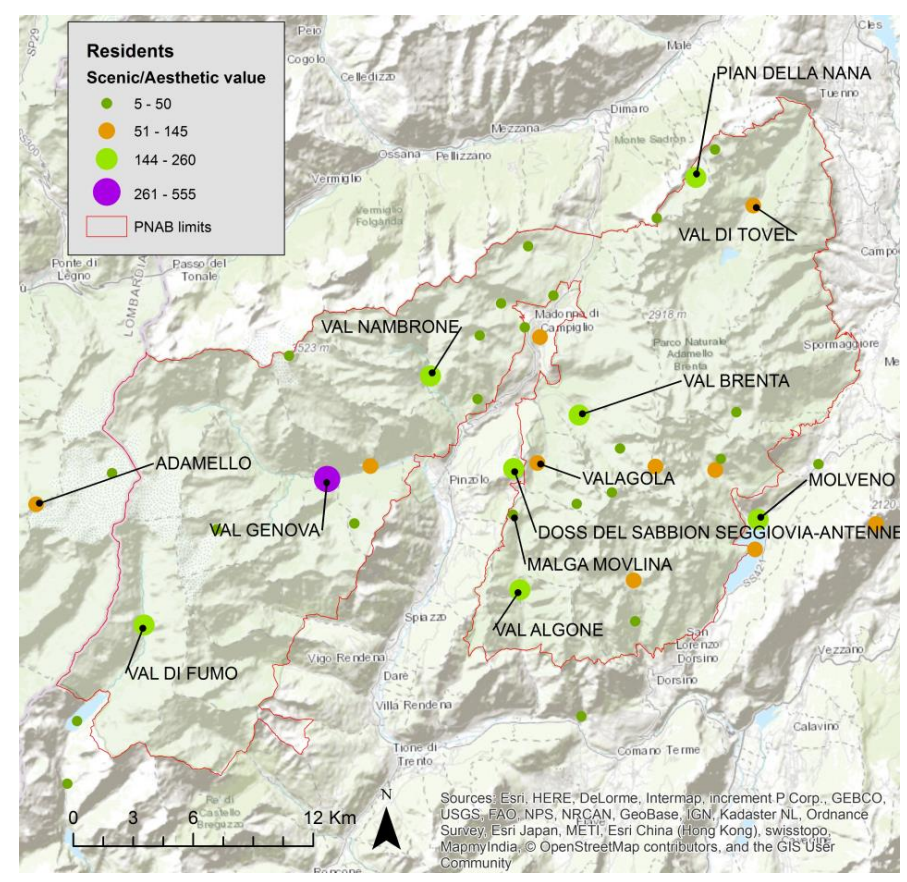

Figure 6: Scenic/aesthetic value for residents. Dots of different colours represent the places mentioned by the participants: the larger the dot, the higher the feature scored. 


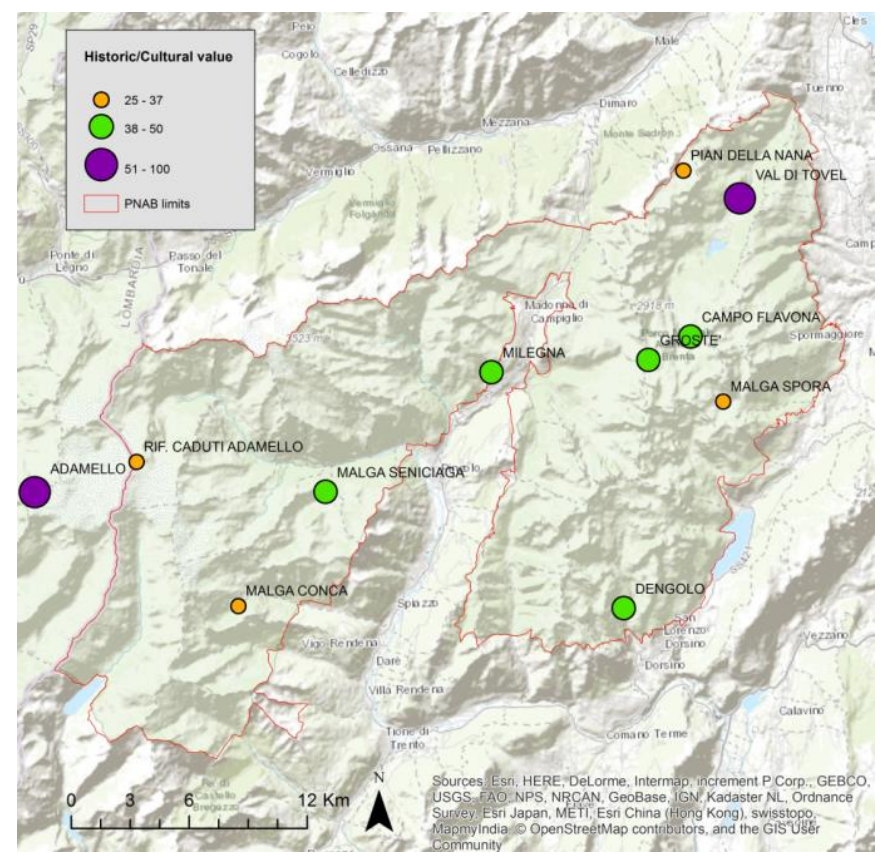

Figure 7: Historic/Cultural value for residents. Dots of different colours represent the places mentioned by the participants: the larger the dot, the higher the feature scored.

\section{The Alto Mayo}

In the present case study, 100 key actors were surveyed within 15 large towns: 60 from public administrations and 40 from important local institutions. Among the 375 inhabitants who completed their surveys, there were 138 teachers, 130 farmers and a minority of other occupations. Surveys were carried out in 12 large towns and 23 small rural towns. The participants comprised 196 new settlers, 127 old settlers, 19 indigenous people and 33 without information.

Both for key actors and for inhabitants, the two most highly-ranked values of landscape ES were the life-sustaining and biodiversity values, while the lowest-ranked ones were the recreational and historic values (Figure 8). The importance of life-sustaining values, such as rivers and biodiversity, seem to be recognized by participants as crucial elements to maintain the quality of life of inhabitants of the area. Moreover, they represent key factors in the conservation and territory planning projects for the San Martín government and other local institutions, such as the Biocuencas Project. This may represent a qualitative way for the projects to understand their acceptance by local people. The two lowest values were expected given the typology of people living in the Alto Mayo region; most settlers are without any historical connection with this area, or work in agriculture and have no 'tourism culture' or alternative possibilities for earning a living.

Spatial analyses for life-sustaining ES for key actors and inhabitants are shown in Figures 910 (SolVES output) and Figures 11-12 (point kernel density maps). The most valuable 
places, according to the SolVES values (indices between 5 and 8), correspond to the forest and aquatic ecosystems, mainly located on the orographic right side of the valley, where most of the population lives. Both the key actors and the inhabitants interviewed identified the main protected areas as very important for biodiversity (Figures 13-14, for SolVES output; Figures 15-16, for point kernel density maps). This is the case for those located in the central part of the valley (SolVES value indices between 7 and 9), which represent the last natural patches in a matrix of anthropic activities, and the most important protected area, that is, the BPAM (value index 5). A SolVES value index of 4 is attributed to the indigenous communities living on the orographic left side of the valley (less affected by human activities).

Through the use of Maxent maximum entropy modelling software, SolVES allows combining the social values of landscape ES distribution with environmental layers. This could help promote discussion of the connections between the values perceived and different environmental characteristics, thus highlighting where these relationships are stronger and also showing up other areas whose environmental characteristics are not mapped directly but have potentially high values. On the other hand, a simple kernel density map has the advantage of showing specific places better. It may also be more useful - for example, in this case, where we want to highlight specific natural tourist sites to prioritize.

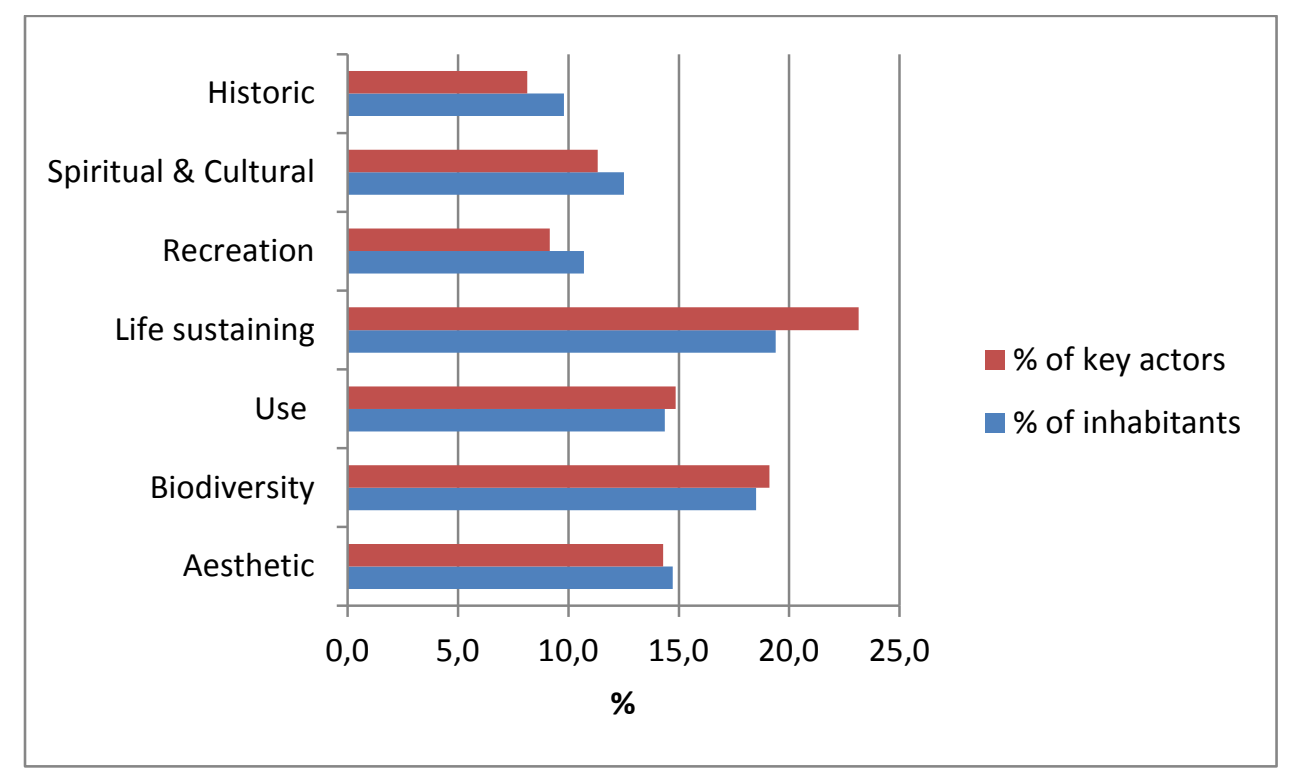

Figure 8: Ranking of social values of landscape ES from surveys of inhabitants and key actors. 

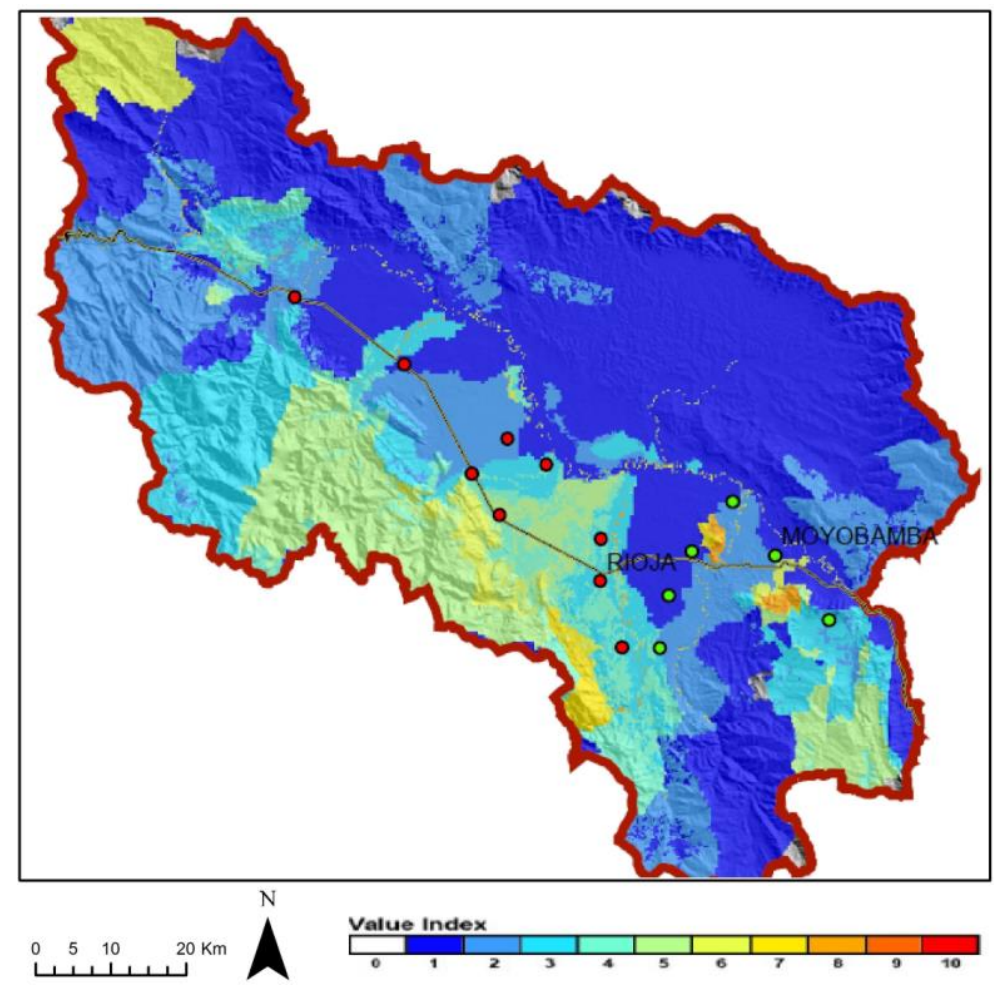

Figure 9: SolVES: surveys of key actors, life-sustaining value. 


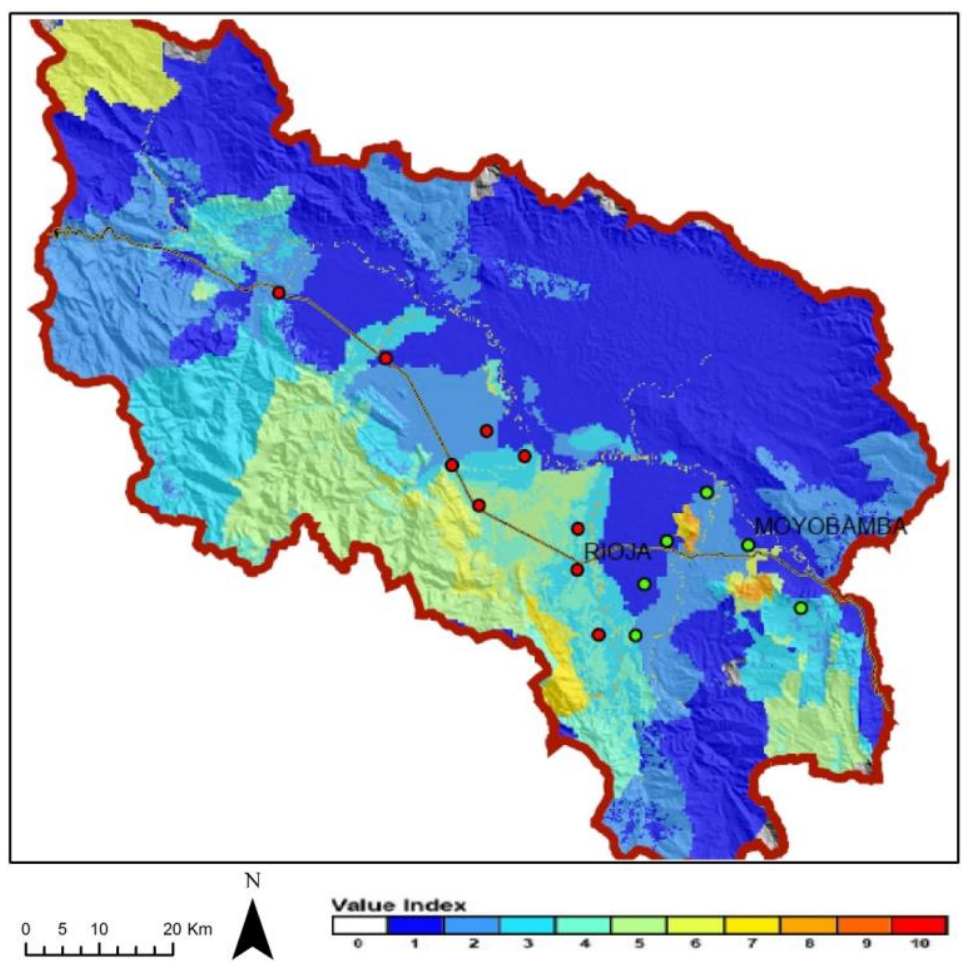

Figure. 10: SolVES: surveys of inhabitants, life-sustaining value.

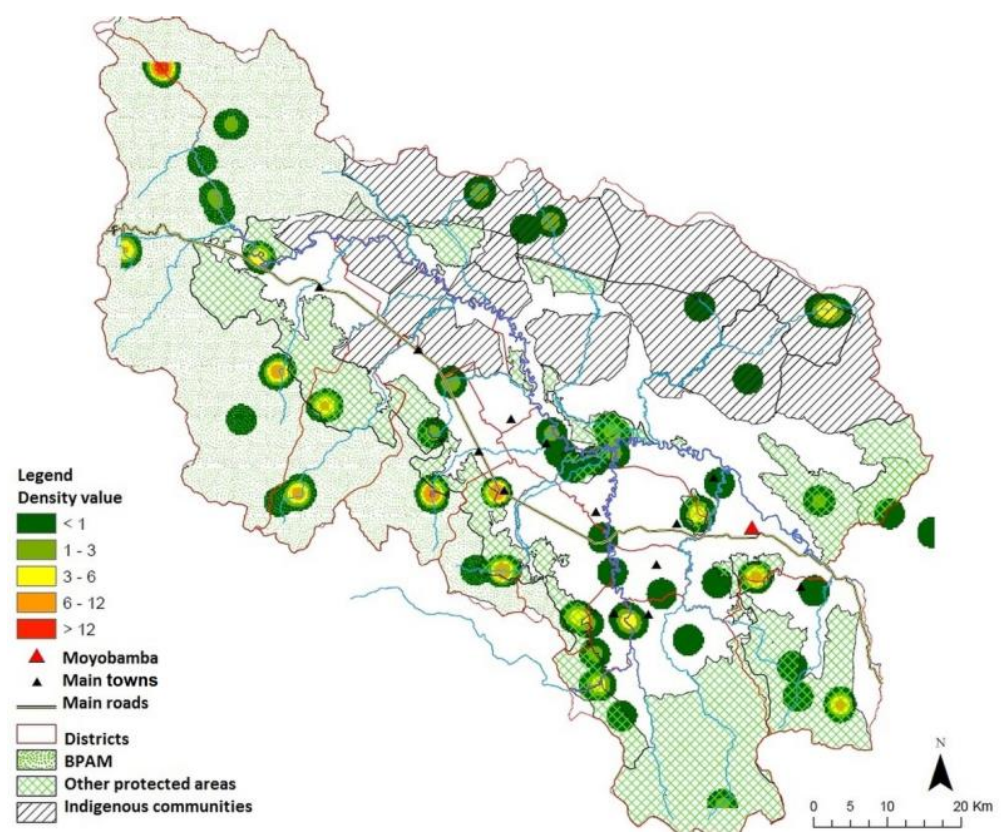

Figure 11: Point kernel density: surveys of key actors, life-sustaining value. 


\section{Codato et al}

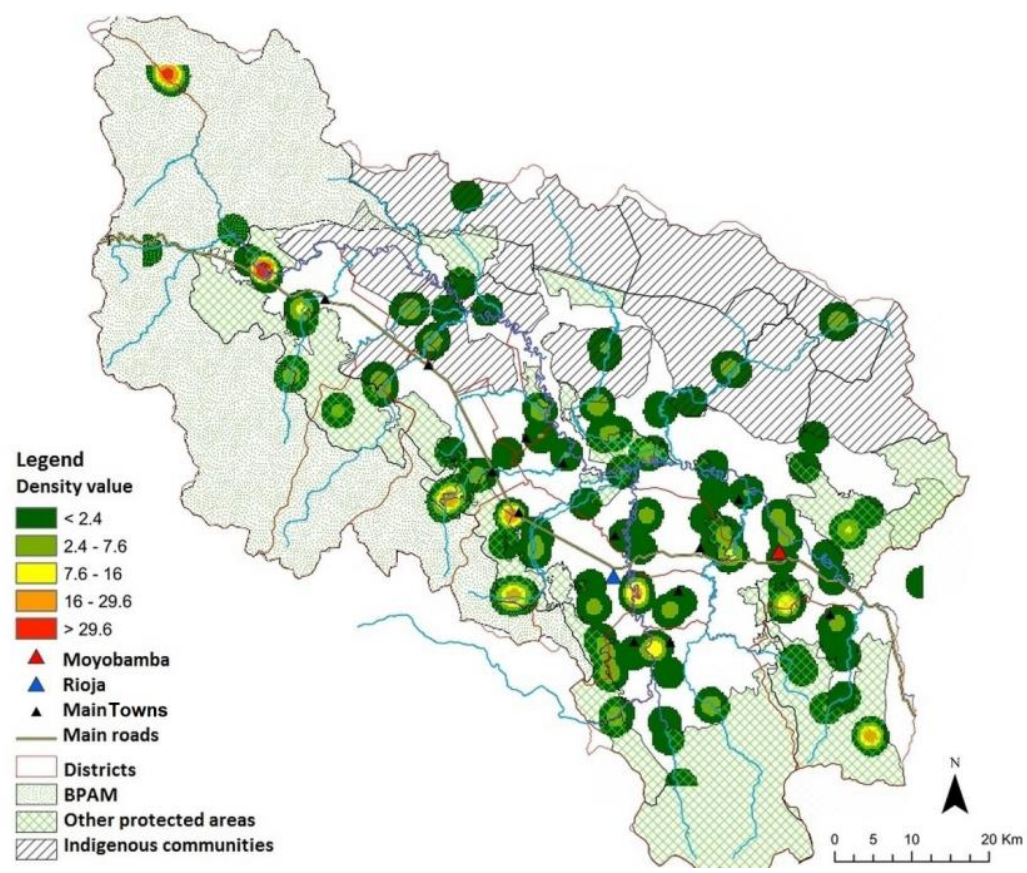

Figure 12: Point kernel density: surveys of inhabitants, life-sustaining value.

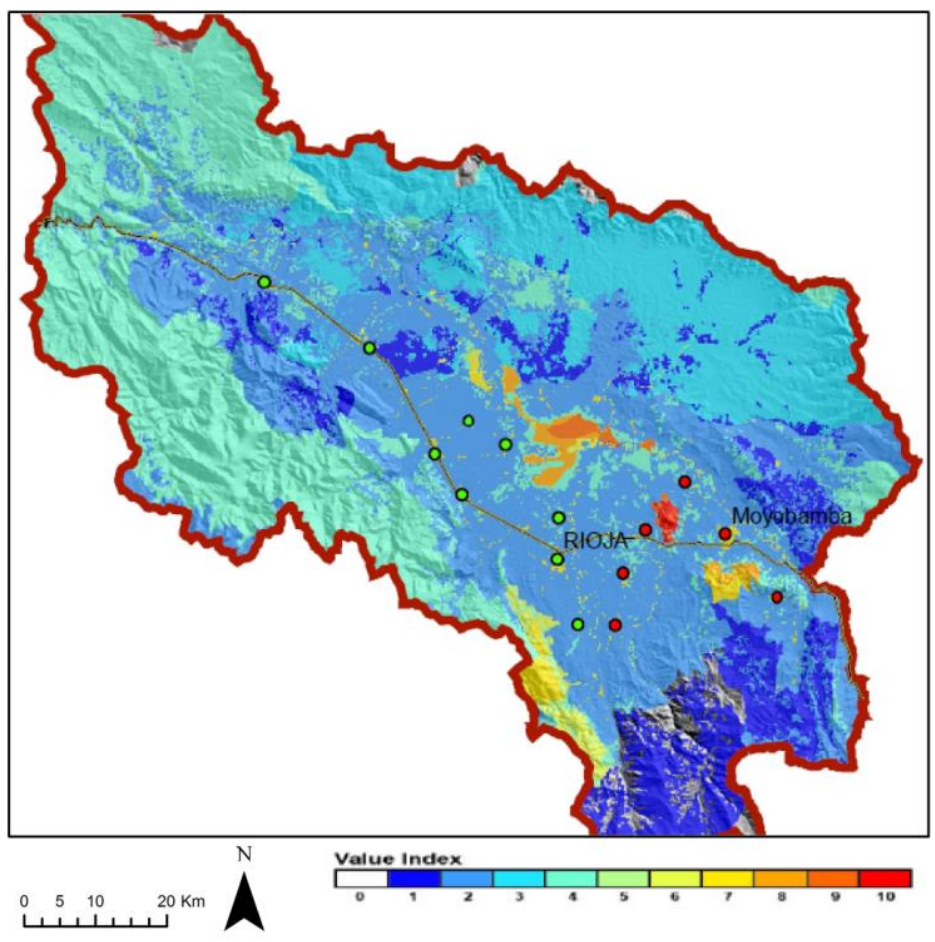

Figure 13: SolVES: interviews with key actors, biodiversity value. 

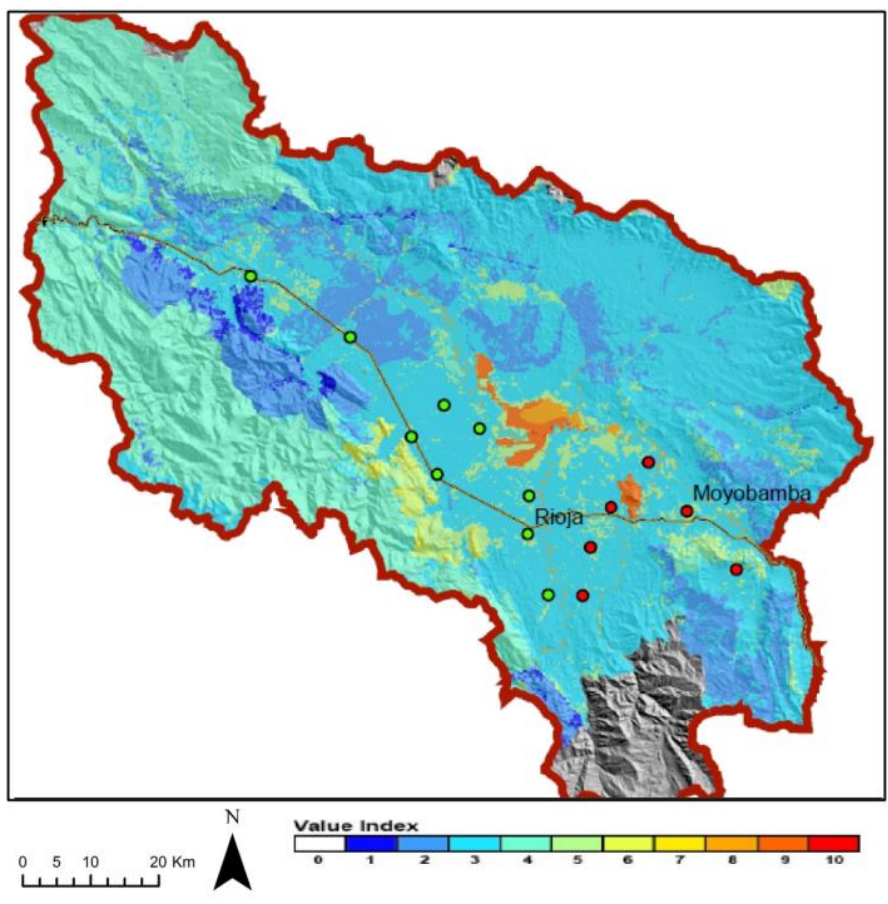

Figure. 14: SolVES: surveys of inhabitants, biodiversity value.

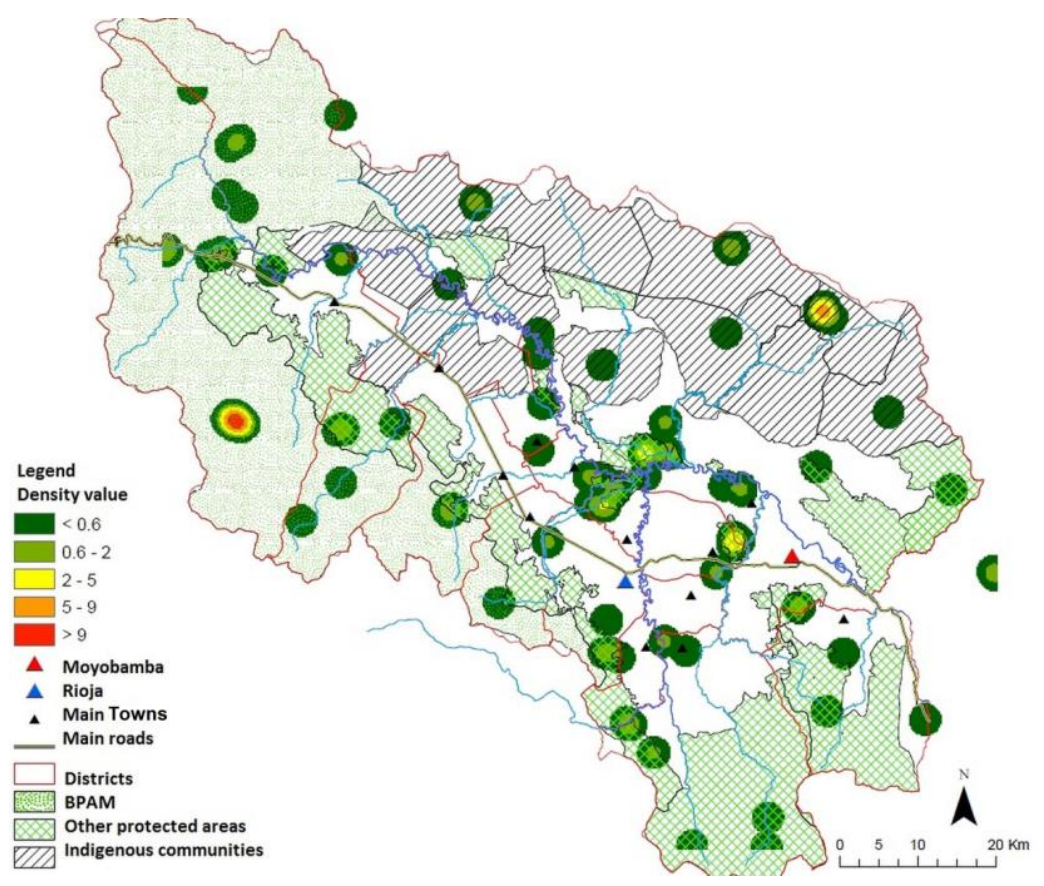

Figure 15: Point kernel density: interviews with key actors, biodiversity value. 


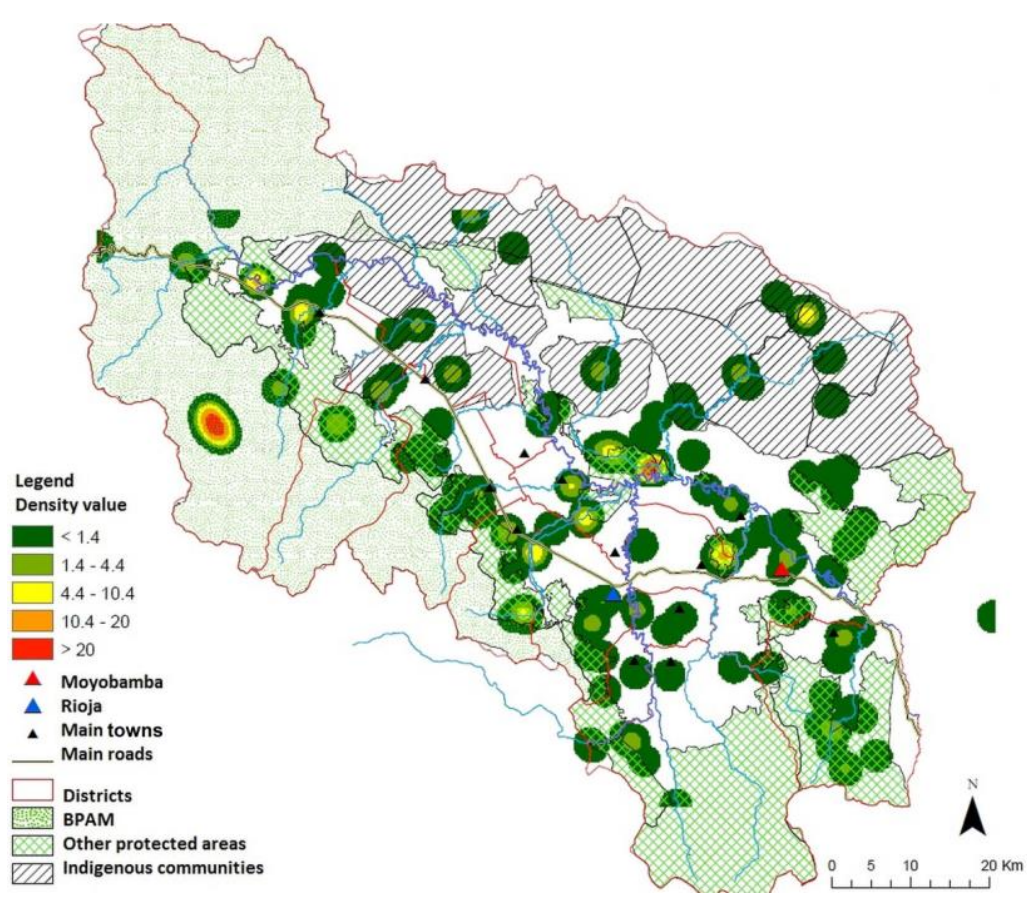

Figure 16: Point kernel density: surveys of inhabitants, biodiversity value.

Comparative analyses of the two case studies show that in the PNAB, social values of landscape ES were particularly important for post-material consumers (scenic-aesthetic for both tourists and residents, and historic-cultural for residents). In the Alto Mayo, ES landscape values were mainly related to directly life-supporting functions, such as providing fresh water and maintaining biodiversity.

It is important to highlight that people surveyed in the PNAB, unlike in Peru, did not identify places and social values of ecosystem services by working on a map; they answered questions posed by researchers (for tourists) or by filling out the questionnaires themselves (for residents).

This approach, even if it reduced survey time, also reduced the number of places each respondent was able to remember (about half of the people were not able to list four places). In Alto Mayo, on the other hand, the use of maps helped respondents, in many cases, to identify four places or areas as requested.

The mapping visualization was carried out by the research team based on the surveys. A simple thematic dot colour and size were chosen to simplify the visualization and reduce the time required to create it. The Italian study area coincides with a protected area; in Alto Mayo, we found a more complex territory with different land uses and protection statuses. Therefore, the use of a tool such as SolVES was more suitable for the latter and the greater processing time required was justified. 
In both cases, the surveys were part of a more complex participatory methodology (working groups, scenario workshops, public meetings, etc.) which aimed to involve people in contributing to important decision-making processes by facilitating their interest in sharing information and their ability to do this: people were not involved in supplying information just for research purposes.

We used a scientific method within a decision-making process, an approach that was first tested by experts in participatory methodologies (including the use of surveys). In Peru, this preliminary testing suggested reducing the number of landscape ES values from 9 to 7 , while in the PNAB reducing the survey time was suggested.

Social and technological contexts also determine the possible methodological approach. In the PNAB, we worked with people who did not want to spend a considerable amount of time on the questionnaires. Therefore, alternatives for the future in this type of context could include transferring the survey from paper to webGIS. In the case of Alto Mayo, the technological divide would require a deeper analysis of people's ability to use technologies, if these are available.

\section{Conclusions}

The case studies took place in two different ecological and cultural contexts in order to help define a methodology that would work in different contexts, with different social actors and different perceptions. Some authors, such as Hein et al. (2006) and Martín-Lopez et al. (2009), highlight the importance of a multi-scale approach for ES evaluation, i.e. one involving spatial and temporal scales, because different types of ES may affect different stakeholders at various institutional levels; their individual actions and interests may affect the same ecosystems in different ways due to the complex human-ecosystem interactions. At the same time, different stakeholders may evaluate social values of landscape ES differently, depending on the scale of the services provided and their own interests in natural resources management (Hein et al., 2006). Questions about ES and place-based values mapped using PPGIS or PGIS concern the scale of the map used, its influence on and relationship with the attributes mapped, and the spatial dimension of the values (Cacciapaglia et al., 2012; Brown and Kitta, 2014; Brown, 2004; Brown 2013).

The two case studies also reveal other challenging elements related to what we are eliciting: social values of landscape ES, ES, and how people might recognize the social values of landscape better than the ecosystem services categories. Brown (2013) deals with the relationship of place-based values and ES by relating them to the Millennium Ecosystem Assessment categories. He raises an important question about 'how much the perception of place-based values arises from the personal experience and knowledge of the participant (i.e., a phenomenological perspective) versus the participant's ability to identify (whether consciously or not) some fundamental structure, pattern, or process in the landscape (i.e., a landscape ecology perspective) that relates to the landscape's capacity to provide various ecosystem services' (Brown, 2013, p. 2). 
As highlighted, maps are not just tools to show the earth's surface; they also have 'extraordinary power' to become proposals for discussion and to pursue shared representations. People have a universal ability to locate and represent the territory in mental maps, or to draw personal places in the sand. It ought, therefore, to be possible to take advantage of this ability to use ES mapping as a participatory tool for sharing awareness about values and alternatives. From paper maps to digital mapping and the availability of web cartography, citizens are given the opportunity to build their own scales of representation, with the only limitation being the availability of information. The digital combination of layers and participatory GIS may open new spaces for the social inclusion of new actors, with regard not only to current territorial representations, but also to future ones. Moreover, in a world of technological globalization, voluntary geography is opening new doors by allowing the manipulation of existing data and the collection of new data, and revealing new forms of geographical exploration. Finally, in facing the challenging tasks of ES representation and evaluation, we should take into account these key issues: How are we mapping, and are we integrating social and expert mapping? What are we mapping, and are we addressing the need to find correspondences between social values and ES? With whom are we mapping, and are we including different actors in the map-making process?

\section{References}

Brown, G. (2004). Mapping Spatial Attributes in Survey Research for Natural Resource Management: Methods and Applications. Society \& Natural Resources, 18(1), 17-39

Brown, G. (2012). Public Participation GIS (PPGIS) for Regional and Environmental Planning: Reflections on a Decade of Empirical Research. URISA Journal, 25(2), 7-18

Brown, G. (2013). The relationship between social values for ecosystem services and global land cover: An empirical analysis. Ecosystem Services, 1-11

Brown, G. \& Kyttä, M. (2014). Key issues and research priorities for public participation GIS (PPGIS). A synthesis based on empirical research. Applied Geography, 46, 122-136

Bryan, B. A., Raymond, C. M., Crossman, N. D., \& Macdonald, D. H. (2010). Targeting the management of ecosystem services based on social values: Where, what, and how? Landscape and Urban Planning, 97(2), 111-122

Cacciapaglia, M. A., Yung, L., \& Patterson, M. E. (2012). Place Mapping and the Role of Spatial Scale in Understanding Landowner Views of Fire and Fuels Management. Society \& Natural Resources, 25(5), 453-467

Codato, D. (2015). Estudio de la percepción social del territorio y de los Servicios Ecosistemicos en el Alto Mayo, Región San Martín. Espacio y Desarrollo, 27, 7-31

De Marchi, M. (2013). Territorio y representaciones: geografía del Yasuní, in Yasuní zona de sacrificio, Análisis de la iniciativa ITT y los derechos colectivos indígenas, Narvaez I, De Marchi M., Pappalardo S. E. (Eds.). FLACSO Ecuador, Quito, 242-275

De Marchi, M. \& Scolozzi, R. (2012). La valutazione economica dei servizi ecosistemici e del paesaggio nel Parco Naturale Adamello Brenta. Valutazione Ambientale, 22, 54-61

Hauck, J., Görg, C., Varjopuro, R., Ratamäki, O., Maes, J., Wittmer, H., \& Jax, K. (2013). 'Maps have an air of authority': Potential benefits and challenges of ecosystem service maps at different levels of decision making. Ecosystem Services, 4, 25-32

Hein, L., van Koppen, K., de Groot, R. S., \& van Ierland, E. C. (2006). Spatial scales, stakeholders and the valuation of ecosystem services. Ecological Economics, 57(2), 209-228 
Hermann, A., Schleifer, S., \& Wrbka, T. (2011). The Concept of Ecosystem Services Regarding Landscape Research: A Review. Living Reviews in Landscape Reseach, 5(1), 1-37

Kwan, M. \& Ding, G. (2008). Geo-Narrative: Extending Geographic Information Systems for Narrative Analysis in Qualitative and Mixed-Method Research. The Professional Geographer, 60(4), 443-465

Martín-López, B., Gómez-Baggethun, E., Lomas, P. L., \& Montes, C. (2009). Effects of spatial and temporal scales on cultural services valuation. Journal of Environmental Management, 90(2), 1050-59

MA - Millennium Ecosystem Assessments (2005). Ecosystem and human well-being: a synthesis. Island press, Washington DC

Nahuelhual, L., Benra Ochoa, F., Rojas, F., Ignacio Diaz, G., \& Carmona, A. (2016). Mapping social values of ecosystem services: What is behind the map? Ecology and Society, 21(3), 24

Nyerges, T., Couclelis H., \& McMaster R. (2011). The SAGE Handbook of GIS and Society. Sage Publications, London

Pappalardo, S.E., De Marchi, M., \& Ferrarese, F. (2013). Uncontacted Waorani in the Yasuní Biosphere Reserve: geographical validation of the Zona Intangible Tagaeri Taromenane (ZITT). PLoS ONE, 8(6), e66293

Rambaldi, G., Kwaku Kyem, P. A., McAll, P., \& Winer, D. (2006). Participatory spatial information management and communication in developing countries. The Electronic Journal of Information System in Developing Countries, 25(1), 1-9

Sherrouse, B. C., Clement, J. M., \& Semmens, D. J. (2011). A GIS application for assessing, mapping, and quantifying the social values of ecosystem services. Applied Geography, 31(2), 748-760

Sherrouse, B. C., Semmens, D. J., \& Clement, J. M. (2014). An application of Social Values for Ecosystem Services (SolVES) to three national forests in Colorado and Wyoming. Ecological Indicators, 36, 68-79

Van Riper, C. J., Kyle, G. T., Sutton, S. G., Barnes, M., \& Sherrouse, B. C. (2012). Mapping outdoor recreationists' perceived social values for ecosystem services at Hinchinbrook Island National Park, Australia. Applied Geography, 35(1-2), 164-173 